\title{
Intracavitary cisplatin-fibrin chemotherapy after surgery for malignant pleural mesothelioma: A phase I trial
}

Isabelle Opitz, MD, ${ }^{\mathrm{a}}$ Olivia Lauk, MD, ${ }^{\mathrm{a}}$ Mayura Meerang, $\mathrm{PhD},{ }^{\mathrm{a}}$ Alexander Jetter, MD, ${ }^{\mathrm{b}}$ Beat Aeschlimann, ${ }^{\mathrm{c}}$ Burkhardt Seifert, $\mathrm{PhD},{ }^{\mathrm{e}}$ Detlef Günther, $\mathrm{PhD},{ }^{\mathrm{c}}$ Rolf A. Stahel, MD, ${ }^{\mathrm{d}}$ and Walter Weder, MD

\section{ABSTRACT}

Objectives: Intracavitary chemotherapy is a promising concept to improve local tumor control for malignant pleural mesothelioma with reported high morbidity rates. We have demonstrated that administration of cisplatin loaded to fibrin increased local drug concentration and reduced systemic toxicity in preclinical models. We present a phase I trial of intracavitary cisplatin-fibrin after surgical tumor resection.

Methods: A total of 12 patients (75\% International Mesothelioma Interest Group stage III-IV) were treated with 4 dose levels of intracavitary cisplatin-fibrin (11-44 $\mathrm{mg} / \mathrm{m}^{2}$ body surface area) in a dose-escalating design. Cisplatin-fibrin was sprayed on the resected surfaces after pleurectomy/decortication. Blood and tissue samples were taken to assess toxicity and pharmacokinetics. Patients were regularly followed up.

Results: No dose-limiting toxicity was observed. Major morbidity occurred in 4 patients $(33 \%)$. The 30 -day and 90 -day mortality were both $0 \%$. Of 80 adverse events, 9 were classified serious, but none of these were related to study treatment. Local cisplatin concentration in the chest wall tissue was high at all dose levels (median, $46.3 \mu \mathrm{g} / \mathrm{g}[12-133 \mu \mathrm{g} / \mathrm{g}]$ ). In serum, median cisplatin area under the concentration time curve values were always below renal toxicity levels. The median overall survival with $95 \%$ confidence interval was 21 months (10-31 months). In 1 patient with epithelioid malignant pleural mesothelioma (International Mesothelioma Interest Group stage I), there was no sign of relapse 48 months after treatment $\left(44 \mathrm{mg} / \mathrm{m}^{2}\right.$ body surface area).

Conclusions: The administration of intracavitary cisplatin-fibrin is safe with favorable pharmacokinetics. Although most patients had advanced disease, long-term outcomes are comparable to other multimodal concepts. A confirmation phase II trial is ongoing. ( $\mathrm{J}$ Thorac Cardiovasc Surg 2020;159:330-40)

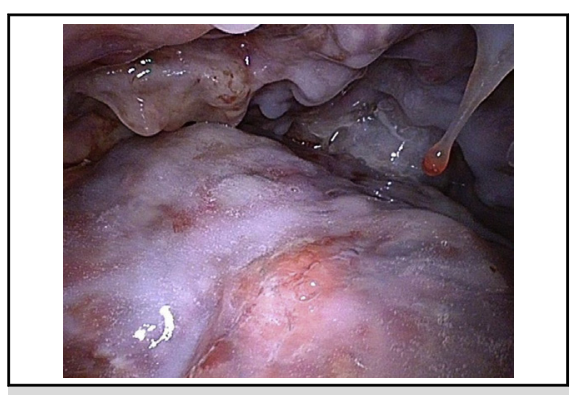

Cisplatin-fibrin formed gel layer on the thoracic wall and the lung surface.

\section{Central Message}

Intracavitary administration of cisplatin loaded with fibrin gel after (extended) pleurectomy/ decortication is safe and feasible at the maximum cisplatin dosage tested while having $0 \%$ mortality and $33 \%$ morbidity.

\section{Perspective}

This new therapy approach with intracavitary cisplatin application after pleurectomy/ decortication is safe and feasible at a cisplatin concentration up to $44 \mathrm{mg} / \mathrm{m}^{2}$ BSA. The application of a concomitant sealant of fibrin is expected to provide continuous and slow drug release and therefore a possible later recurrence rate. Further studies are warranted to investigate even higher dose applications than used in our study.

See Commentaries on pages 341 343 , and 344.
Local recurrence is the most important success-limiting factor in the treatment of patients with malignant pleural mesothelioma (MPM). Although overall survival (OS) data

From the Departments of ${ }^{\mathrm{a}}$ Thoracic Surgery, ${ }^{\mathrm{b}}$ Clinical Pharmacology and Toxicology, and ${ }^{\mathrm{d}}$ Laboratory of Molecular Oncology, University Hospital Zurich, Zurich, Switzerland; ' Department of Chemistry and Applied Biosciences and Laboratory of Inorganic Chemistry, ETH Zurich, Zurich, Switzerland; and ${ }^{\mathrm{e}}$ Department of Biostatistics, Epidemiology, Biostatistics, and Prevention Institute, University of Zurich, Zurich, Switzerland.

The work was supported by the Swiss National Science Foundation (Grant Number: PP00P3_133657, PP00P3_159269) and Vivostat SA. Neither Swiss National Science Foundation nor Vivostat had any function in the study design, writing of the report, or decision to submit the article for publication.

Clinical trial registry number: NCT01644994. for patients with MPM were positively influenced by multimodal treatment concepts including surgery and chemotherapy over the last decade, local recurrences occur after a

\footnotetext{
Date and number of Institutional Review Board approval: 14.05.2012 KEK-ZH Nr. 2012-0205.

Received for publication Dec 28, 2018; revisions received July 24, 2019; accepted for publication July 24, 2019; available ahead of print Oct 5, 2019.

Address for reprints: Isabelle Opitz, MD, Department of Thoracic Surgery, University Hospital Zurich, Raemistrasse 100, 8091, Zurich, Switzerland (E-mail: isabelle. schmitt-opitz@usz.ch). $0022-5223 / \$ 36.00$

Copyright $(\subset) 2019$ by The American Association for Thoracic Surgery https://doi.org/10.1016/j.jtcvs.2019.07.073
} 

Abbreviations and Acronyms
$\mathrm{AE}=$ adverse event
AUC = area under the curve
BSA = body surface area
CI $=$ confidence interval
$\mathrm{CT}=$ computed tomography
$\mathrm{CTCAE}=$ Common Terminology Criteria for
Adverse Events
FFR $=$ freedom from recurrence
MPM = malignant pleural mesothelioma
OS = overall survival
POD $=$ postoperative day
SAE $=$ serious adverse event

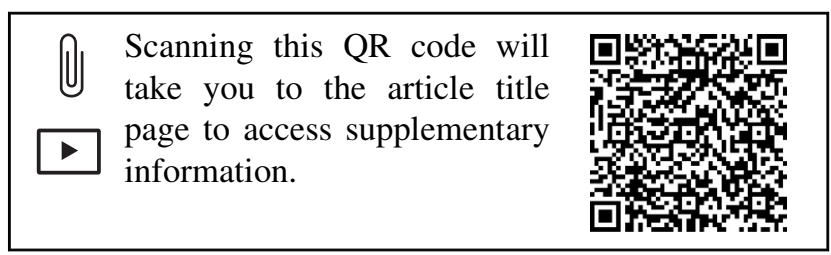

median of 6 to 14.4 months. ${ }^{1-5}$ Therefore, new treatment strategies are required to improve local tumor control.

One particular concept for a better local tumor control is intracavitary chemotherapy after maximal cytoreductive surgery. Several groups proved the feasibility of intrapleural cisplatinbased chemotherapy with or without hyperthermia in clinical phase I or II studies. ${ }^{6-11}$ One of the major drawbacks of this application form is the rapid absorption of the drug applied, leading to high systemic concentrations and treatment-related morbidity up to $65 \%$ and mortality up to $11 \% .^{12,13}$

With the aim to reduce the systemic absorption rate of intracavitarily administered cisplatin and increase drug exposure in tissues, we combined cisplatin with fibrin gel (Vivostat; Vivostat SA, Alleroed, Denmark), a semi-solid drug carrier that can adhere to tissue and is used for hemostasis ${ }^{14}$ and air leak sealing after lung surgery. ${ }^{15}$ In preclinical animal models, intracavitary cisplatin-fibrin increased local drug concentration in tissues and reduced systemic distribution of cisplatin and renal toxicity compared with cisplatin applied as solution with the same efficacy in reduction of local tumor recurrence after resection. ${ }^{16-18}$

The aim of this present clinical phase I trial is to introduce this new therapeutic method of intracavitary chemotherapy with cisplatin-fibrin after surgical resection in patients and to study the safety and the maximum tolerated dose.

\section{MATERIAL AND METHODS \\ Outcome Variables}

The primary objectives of this phase I study were to determine the safety (adverse events [AEs] and blood analysis for bone marrow and renal toxicity) and the local cisplatin concentration in the superficial tissue of the chest wall after localized intracavitary cisplatin-fibrin application after mesothelioma resection.

The secondary objectives were to determine the efficacy (OS, freedom from recurrence $[\mathrm{FFR}]$ ) of intracavitary cisplatin-fibrin. Moreover, the pharmacokinetics of cisplatin-fibrin was to be studied by analysis of cisplatin concentrations in the serum, urine, pleural effusion, and superficial tissue of the chest wall. The selection of starting dosage and dose escalation scheme is explained in detail in Appendix E1.

\section{Patients' Characteristics}

From November 2012 to October 2014, 57 patients with a diagnosis of MPM were eligible for the present study. A total of 45 patients were excluded because of strict selection criteria (Table E1); therefore, 12 patients underwent the full treatment protocol, 8 of whom received previous intravenous induction chemotherapy with cisplatin/pemetrexed (3 cycles of cisplatin $80 \mathrm{mg} / \mathrm{m}^{2}$ and pemetrexed $500 \mathrm{mg} / \mathrm{m}^{2}$ on day 1 administered every 21 days with vitamin supplementation) (Figure 1 and Online Data Supplement). No female patients were enrolled in the study. The median time gap after last cycle of chemotherapy and surgery was 27 days (range, 15-42 days). Patients did not receive any other treatment postresection. The decision for resection was made during interdisciplinary tumor board discussion. None of the patients underwent extrapleural pneumonectomy. Patients' characteristics and staging (according to TNM Classification of Malignant Tumours, 7th Edition) are shown in Table 1, and inclusion and exclusion criteria are shown in Table E1.

The study was conducted in compliance with the protocol, the current version of the Declaration of Helsinki, International Conference on Harmonisation-Good Clinical Practice, and all national legal and regulatory requirements (Study Permit No. KEK-ZH-Nr. 2012-0205/Swissmedic Ref. Nr. 2012DR1111). All patients gave written informed consent after study information was provided.

\section{Study Treatment}

(Extended) pleurectomy/decortication was performed as described previously at our institution. ${ }^{19}$ After resection, the chest wall was provisionary closed for cisplatin-fibrin application by means of video-assisted thoracic surgery (Figure 2) for video guidance of application and to minimize the risk of cisplatin exposure for staff (Video 1). Methods describing fibrin preparation procedure and codelivery of cisplatin-fibrin is described in Appendix E1.

Cisplatin-fibrin was applied on the resection surface of the pleura on the chest wall, the mediastinum, pericardium, and diaphragm (if not resected and reconstructed), and the lung tissue (Figure 2).

\section{Cisplatin Pharmacokinetics}

Tissue was collected at surgery (baseline) and 90 minutes after cisplatin-fibrin application to determine local cisplatin concentration. At 90 minutes, tissue was always collected from the fifth intercostal space by thoracoscopic biopsy. At 90 minutes, after the end of cisplatin-fibrin administration, the covering gel layer was removed using a surgical forceps followed by tissue biopsy from the chest wall underneath using the same forceps that was thoroughly rinsed to remove any residual gel or cisplatin. Serial blood samples were collected at baseline (before spraying) and at 2 , $6,8,10,24,48$, and 120 hours after treatment, as well as urine samples before, during the first 48 hours, and 14 days after treatment. Serum was collected after centrifugation at $1200 \mathrm{~g}$ for 10 minutes. All samples were stored at $-80^{\circ} \mathrm{C}$ until analysis. Pleural effusion was collected during 48 hours after the treatment from level $22 \mathrm{mg} / \mathrm{m}^{2}$ onwards.

Total platinum concentration in these blood, urine, tissue, pleural effusion, and gel samples was determined with a double focusing magnetic sector field inductively coupled plasma mass spectrometry with the calibration based on standard addition. ${ }^{20}$ 


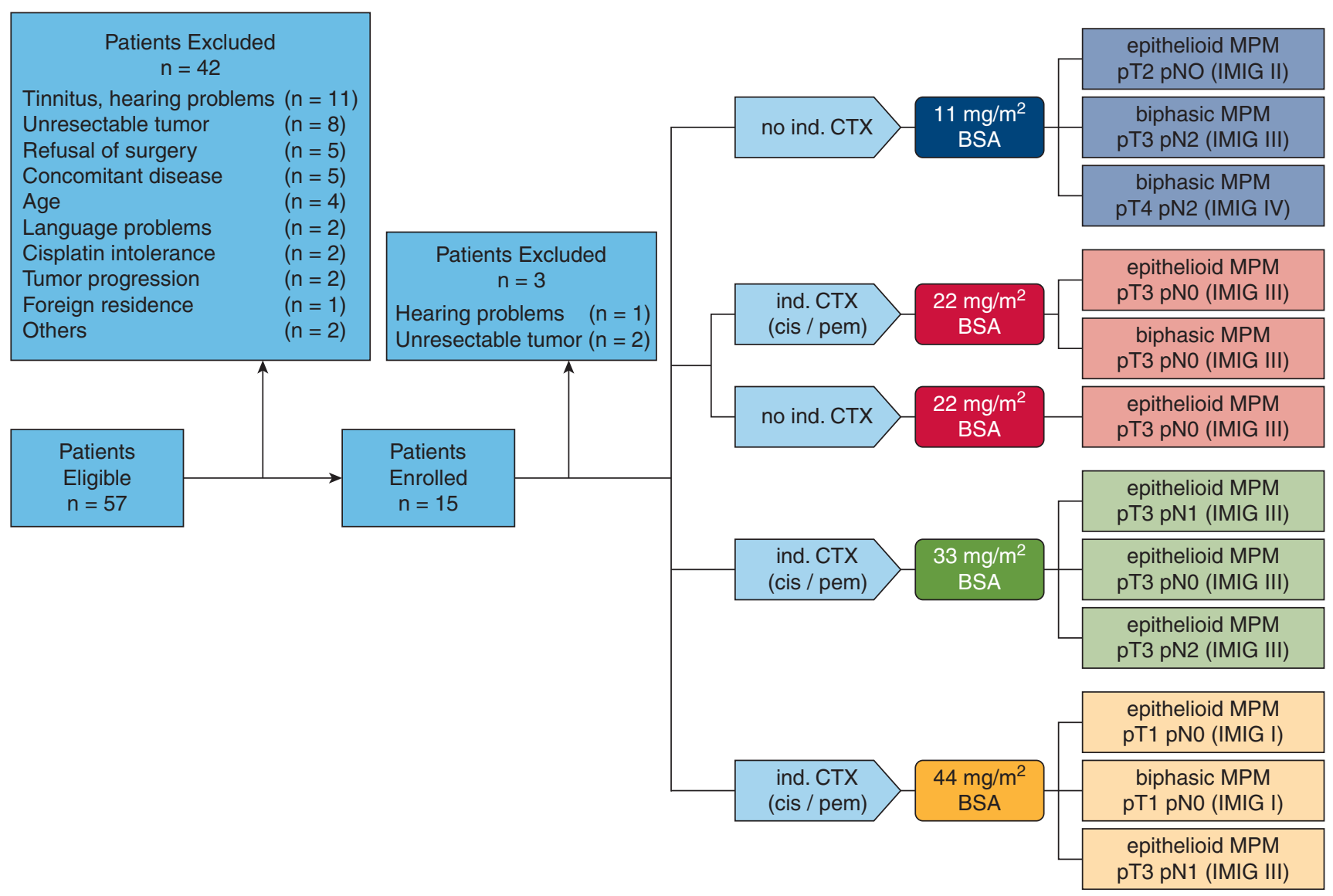

FIGURE 1. Diagram describing patient selection and enrollment in the INFLuenCe-Meso I clinical trial. CTX, chemotherapy; ind.CTX, induction chemotherapy; $B S A$, body surface area; MPM, malignant pleural mesothelioma; IMIG, International Mesothelioma Interest Group; cis/pem, cisplatin/pemetrexed.

\section{Safety Assessment}

AEs were assessed up to 42 days (visit $5=4$ weeks \pm 14 days) after application of cisplatin-fibrin, and serious adverse events (SAEs) were assessed up to 126 days (visit $7=16$ weeks \pm 14 days) because there was no relation to the cisplatin-fibrin single dose application to be expected thereafter. An exception beyond those time points would be a suspected causal relationship (Table 2).

Acute and late toxicities were recorded according to the Common Terminology Criteria for Adverse Events (CTCAE), version 4.03 (June, 2010). Laboratory data included hematology and serum values taken at visits 1 and 2, at baseline before surgery, postoperative days (PODs) 1, 2, $3,4,5,7,10$, and 14 , and at visits 5 and 6 . Major morbidity was defined by any complication/morbidity necessitating reoperation, empyema, bronchopleural fistula, chylothorax, patch failure, pulmonary embolism, or acute respiratory distress syndrome.

\section{Follow-up and Assessment of Treatment Efficacy}

Patients underwent regular follow-up visits at our clinic, including computed tomography (CT) and 18F-fluoro-2-deoxy-D-glucose positron-emission tomography (FDG-PET) CT/magnetic resonance imaging every 4 months to detect tumor progression. The study schedule is shown in Table E2. The efficacy of the treatment was determined by assessment of OS and FFR.

\section{Statistics}

OS and FFR were calculated from date of first treatment until death and tumor relapse (histologically confirmed or radiologically in serial imaging). If no event occurred, the OS and FFR were calculated until the last date of follow up and censored in the analysis. Median survival was analyzed using the Kaplan-Meier method.

Pharmacokinetics of cisplatin in serum were calculated using a noncompartmental model with the software Phoenix WinNonlin (Version 6.3, Certara Inc., St Louis, Mo). The area under the concentration versus time curve during the first 24 hours $\left(\mathrm{AUC}_{0-24}\right)$, and the maximum serum concentration after thoracic surgery $\left(\mathrm{C}_{\max }\right)$ were the primary pharmacokinetic characteristics for evaluation. Although $\mathrm{C}_{\max }$ and $\mathrm{T}_{\max }$ (the time, which elapsed until $\mathrm{C}_{\max }$ was reached) were directly taken from the concentration data, area under the curve (AUC) was calculated using the trapezoidal rule, as implemented in the software package Phoenix. Because some patients received neoadjuvant intravenous induction chemotherapy with cisplatin before cisplatin-fibrin application, these patients had quantifiable cisplatin concentrations in the serum samples obtained before intracavitary cisplatin application, and a correction of the cisplatin AUC values was necessary for later comparison. To this end, the actual serum cisplatin concentration before the application of cisplatin-fibrin was the starting point for an extrapolation to infinity. ${ }^{21}$ The part of the resulting extrapolated AUC that corresponded to the first 24 hours was then subtracted from the total $\mathrm{AUC}_{0-24}$ obtained after application of the intracavitary cisplatin-fibrin.

Cisplatin concentrations in tissues and gel were reported as they were. For urine and pleural effusion, the concentration was multiplied by the amount of collected liquid to obtain the amount of cisplatin excreted in urine or recovered in pleural fluid. 
TABLE 1. Patients' characteristics

\begin{tabular}{|c|c|}
\hline Male gender & $12(100 \%)$ \\
\hline Median age at surgery & $64(40-75)$ \\
\hline Right-sided MPM & $7(58 \%)$ \\
\hline Asbestos exposure & $9(75 \%)$ \\
\hline Former smoker & $5(42 \%)$ \\
\hline $\begin{array}{l}\text { Neoadjuvant chemotherapy } \\
\text { (cisplatin and pemetrexed) }\end{array}$ & $8(67 \%)$ \\
\hline ASA 2 & $9(75 \%)$ \\
\hline ASA 3 & $3(25 \%)$ \\
\hline $\begin{array}{l}\text { Histologic subtype } \\
\text { epithelioid } \\
\text { biphasic }\end{array}$ & $\begin{array}{l}8(67 \%) \\
4(33 \%)\end{array}$ \\
\hline pT 1 & $2(17 \%)$ \\
\hline pT 2 & $1(8 \%)$ \\
\hline pT 3 & $8(67 \%)$ \\
\hline pT 4 & $1(8 \%)$ \\
\hline pNO & $7(58 \%)$ \\
\hline $\mathrm{pN} 1 / 2$ & $5(42 \%)$ \\
\hline \multicolumn{2}{|l|}{ Pathological IMIG stage } \\
\hline I & $2(17 \%)$ \\
\hline II & $1(8 \%)$ \\
\hline III & $8(67 \%)$ \\
\hline IV & $1(8 \%)$ \\
\hline
\end{tabular}

MPM, Malignant pleural mesothelioma; ASA, American Society of Anesthesiologists; $I M I G$, International Mesothelioma Interest Group.

\section{RESULTS}

\section{Morbidity, Mortality, and Toxicity}

The median hospital stay was 18 days (range, 14-40), and the minimum stay was 14 days according to study protocol. The overall 30- and 90-day mortality was $0 \%$, and major morbidity rate was $33 \%$ (4 patients).

During the entire study period, no dose-limiting toxicity was observed in all 12 study patients. Of 80 AEs in 12 patients, 9 were classified as SAEs $(6$ unrelated and 3 unlikely related to study treatment, and 6 related to surgery), but none were suspected unexpected serious adverse reactions (Table 2). The only AE determined as possibly related to intracavitary cisplatin-fibrin was the occurrence of tinnitus in 1 patient. Two of these 9 SAEs were rated as grade II (moderate), 4 were rated as grade III (severe), and 3 were rated as grade IV (life-threatening). The most frequent SAE reported was asystole in 2 patients (3 events).

Hematologic and renal toxicity were further assessed via blood analyses on PODs 1, 2, 3, 4, 5, 7, 10, and 14 . Creatinine levels were within normal range in approximately all patients at day 6 and never exceeded CTCAE grade III $(319 \mu \mathrm{mol} / \mathrm{L})$ in all patients, with the exception of 1 patient who had a postoperative hypovolemic shock (Figure 3). Hemoglobin values decreased after 1 to 5 days and returned in approximately all cases to preoperative level (Figure 3) and were primarily grade III anemia (CTCAE grade III; $79 \mathrm{~g} / \mathrm{L}$ ) related to blood loss during surgery.

\section{Tissue, Serum, and Urinary Cisplatin Concentrations}

High concentration of cisplatin was detected in local chest wall tissues at 90 minutes after cisplatin-fibrin administration in all dose levels. Tissue cisplatin levels were highly variable and did not seem to be dose dependent (Figure 4, A). High cisplatin concentrations were detected in deeper chest wall tissues (tissue layer directly underneath the superficial layer from the same location obtained in a second step including more of the intercostal muscles) analyzed in 3 patients (Figure E1). Although a substantial level of cisplatin (median $0.37 \mu \mathrm{g} / \mathrm{g}$ ) was detected at time zero/baseline in the serum of 8 patients receiving intravenous induction chemotherapy before cisplatinfibrin administration, only low to undetectable levels of cisplatin were detected in tissues at baseline (Figure 4, $A$ ). Tissue biopsies and fibrin gels for cisplatin determination were collected from 2 patients, who underwent redo surgery. Empyema was the reason for reoperation of both patients; this was considered an SAE for only 1 patient (day 74). Cytotoxic cisplatin levels were present in tissues until day 74 after the treatment (Figure 4, B).

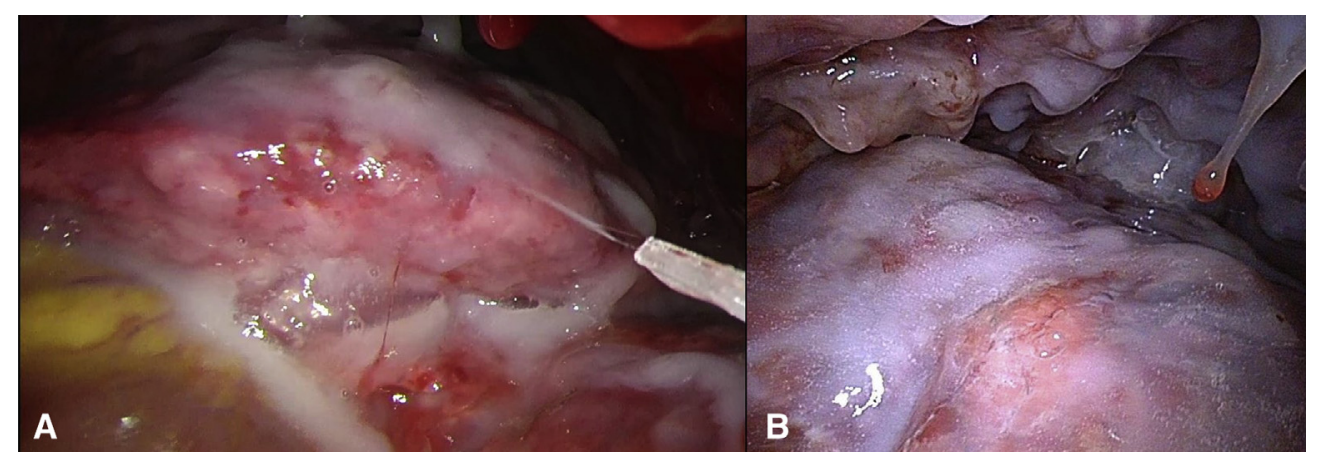

FIGURE 2. Thoracoscopic view during intracavitary cisplatin-fibrin application. A, The spray-pen applying cisplatin-fibrin on collapsed lung (bottom). $\mathrm{B}$, Cisplatin-fibrin forms white gel layer on the thoracic wall (upper) and lung surface (lower). 
TABLE 2. Adverse events and serious adverse events

\begin{tabular}{|c|c|c|c|c|c|}
\hline AE count & Dose level & Diagnosis & Severity CTC grade & Surgical complication & SAE \\
\hline 11 & $11,22,33$, and 44 & Loss of appetite, nausea, or vomiting & I-II & No & No \\
\hline 9 & $11,22,33$, and 44 & Increased heart enzymes & I & Yes & No \\
\hline 8 & $11,22,33$, and 44 & Anemia & III & Yes & No \\
\hline 8 & $11,22,33$, and 44 & Increased creatinine and urea & I-III & No & No \\
\hline 8 & 11,33 , and 44 & Increased liver enzymes & I-IV & No & No \\
\hline 4 & 33 , and 44 & Prolonged air leak & II & Yes & No \\
\hline 3 & 22 and 33 & Thrombocytopenia & I & No & No \\
\hline 3 & 11,22 , and 44 & Hypotension & I-III & No & No \\
\hline 2 & 33 and 44 & Decubitus & II & Yes & No \\
\hline 1 & 22 & Empyema & III & Yes & Yes \\
\hline 1 & 44 & Asystole (short time, with rapid recovery) & IV & & Yes \\
\hline 1 & 22 & Asystole (underlying: sick sinus syndrome) & II & No & Yes \\
\hline 1 & 22 & Asystole (underlying: sick sinus syndrome) & IV & No & Yes \\
\hline 1 & 22 & Atrial fibrillation & II & Yes & No \\
\hline 1 & 44 & Atrial fibrillation with spontaneous conversion & I & Yes & No \\
\hline 1 & 44 & Cardiogenic shock with forward failure & IV & No & Yes \\
\hline 1 & 22 & Chylothorax & II & Yes & No \\
\hline 1 & 33 & Delirium & I & No & No \\
\hline 1 & 33 & Dislocation of the heart & III & Yes & Yes \\
\hline 1 & 44 & Exacerbation of thoracic pain & III & Yes & Yes \\
\hline 1 & 11 & Fatigue & II & No & No \\
\hline 1 & 44 & Fever & II & No & No \\
\hline 1 & 44 & Increased INR & I & No & No \\
\hline 1 & 11 & Pneumothorax & II & Yes & No \\
\hline 1 & 44 & Pneumothorax & II & Yes & Yes \\
\hline 1 & 33 & Postsurgery depression & II & No & No \\
\hline 1 & 22 & Presyncope & II & No & No \\
\hline 1 & 44 & Pulmonary embolism & III & Yes & Yes \\
\hline 1 & 33 & Sleeping disorder & III & No & No \\
\hline 1 & 22 & Tachycardia (Atrovent*-induced) & II & No & No \\
\hline 1 & 33 & Tinnitus & I & No & No \\
\hline 1 & 22 & Toothache & I & No & No \\
\hline 1 & 11 & Urinary retention & II & No & No \\
\hline
\end{tabular}

A concentration of $2.5 \mu \mathrm{mol} / \mathrm{L}(0.75 \mu \mathrm{g} / \mathrm{g}$; cytotoxic concentration) cisplatin was tested to be effective at inhibiting cell proliferation of most of MPM cell lines during short-term exposure (5 days) (unpublished data, cisplatin MPM growth and survival assays, various dates). This is in line with various publications showing the effects of cisplatin in MPM cell lines. ${ }^{22,23}$ Cisplatin was detectable in tissues collected from patient 12 even at day 204 after the treatment (Figure 4, $C$ ).

In all dose levels, median times to the maximum concentration (Tmax) in serum were 2 hours after cisplatin-fibrin administration (Figure 5, A). Median maximum serum cisplatin concentrations (Cmax) from level 1 to 4 were $0.21 \mu \mathrm{g} / \mathrm{g}, 0.47 \mu \mathrm{g} / \mathrm{g}, 1.01 \mu \mathrm{g} / \mathrm{g}$, and $2.06 \mu \mathrm{g} / \mathrm{g}$, respectively. Cisplatin area under the concentration time curve $\left(\mathrm{AUC}_{0-24 \mathrm{~h}}\right)$ levels are depicted in Figure 5, B. Patients in dose levels 2 to 4 received intravenous induction chemotherapy with cisplatin before cisplatin-fibrin and consequently had quantifiable cisplatin serum concentrations before the cisplatin-fibrin application. By subtracting serum cisplatin exposure due to induction chemotherapy by extrapolation, we observed lower 


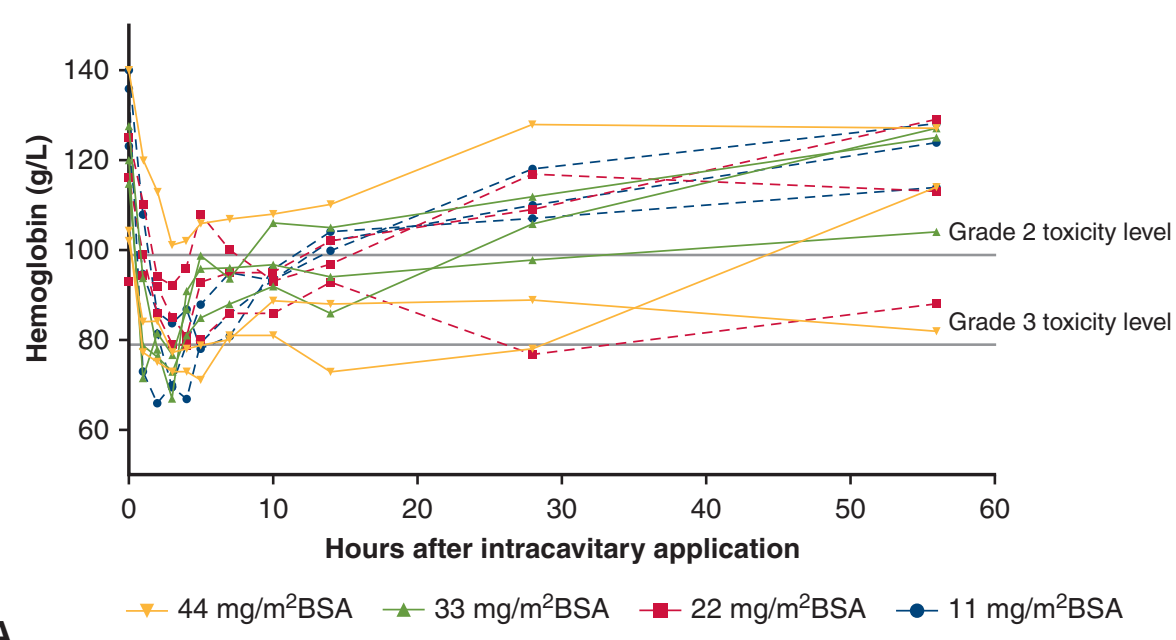

A

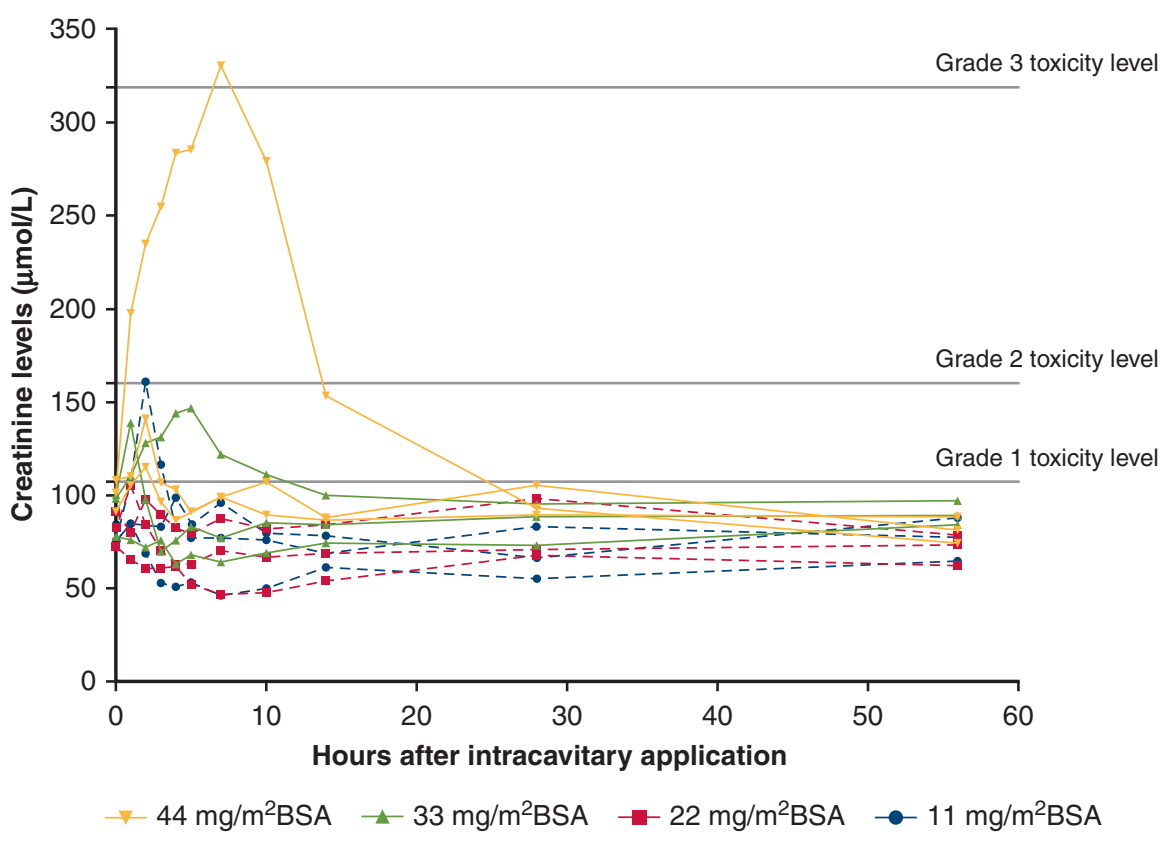

FIGURE 3. Assessment of blood parameters reflecting hematologic and renal toxicity in 12 patients with MPM receiving 4 different dosages of cisplatin-fibrin (11, 22, 33, and $44 \mathrm{mg} / \mathrm{m}^{2}$ BSA; $\mathrm{n}=3$ per group) after (extended) pleurectomy/decortication. Hemoglobin (A) and creatinine (B) levels were measured on day $0,1,2,4,5,7,10$, and 14 , and at 4 and 8 weeks after intracavitary treatment with cisplatin-fibrin. Hemoglobin: CTCAE grade II toxicity limit $=99 \mathrm{~g} / \mathrm{L}$, grade III toxicity limit $=79 \mathrm{~g} / \mathrm{L}$. Serum creatinine: CTCAE grade I toxicity limit $=107 \mu \mathrm{mol} / \mathrm{L}$, grade II toxicity limit $=160 \mu \mathrm{mol} / \mathrm{L}$, grade III toxicity limit $=319 \mu \mathrm{mol} / \mathrm{L} . B S A$, Body surface area.

maximum $\mathrm{AUC}_{0-24 \mathrm{~h}}$ values (Figure 5, B), which was far lower than the suggested renal toxicity limit of approximately $25 \mathrm{~h} * \mu \mathrm{g} / \mathrm{g} .{ }^{24,25}$

We collected urine and pleural effusion up to 48 hours after intracavitary cisplatin application. The median total amount of cisplatin found per dose level is depicted in Figure 5, C. Spot analysis of urine at POD 14 showed a clear and strong decrease of cisplatin levels to $5 \%$ to $18 \%$ of the baseline within 2 weeks. The excretion of cisplatin in the pleural effusion during the first 48 hours was independent of the dose applied (Figure 5, C).

\section{Long-Term Outcome}

Although this dose-escalating study was not designed to investigate efficacy or benefit of the cisplatin-fibrin on OS or FFR and $75 \%$ of patients were in IMIG stage III and IV, we performed preliminary survival analyses. Median follow-up time was 20 months (range, 11-65), and 1 patient 


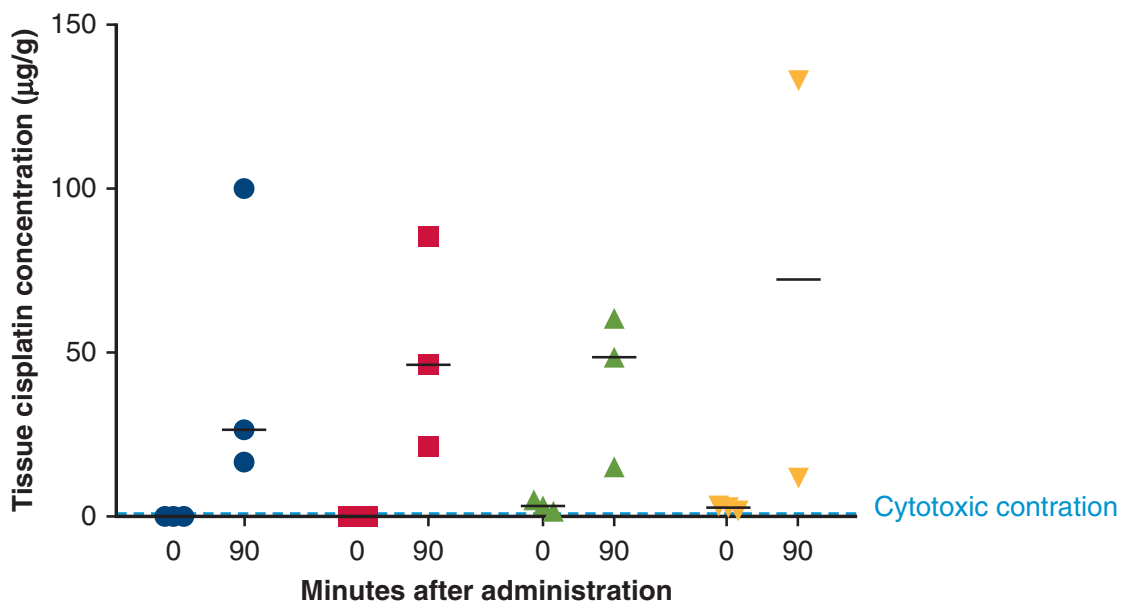

A

- $11 \mathrm{mg} / \mathrm{m}^{2}$ BSA $\quad 22 \mathrm{mg} / \mathrm{m}^{2}$ BSA $\triangle 33 \mathrm{mg} / \mathrm{m}^{2}$ BSA $\nabla 44 \mathrm{mg} / \mathrm{m}^{2}$ BSA
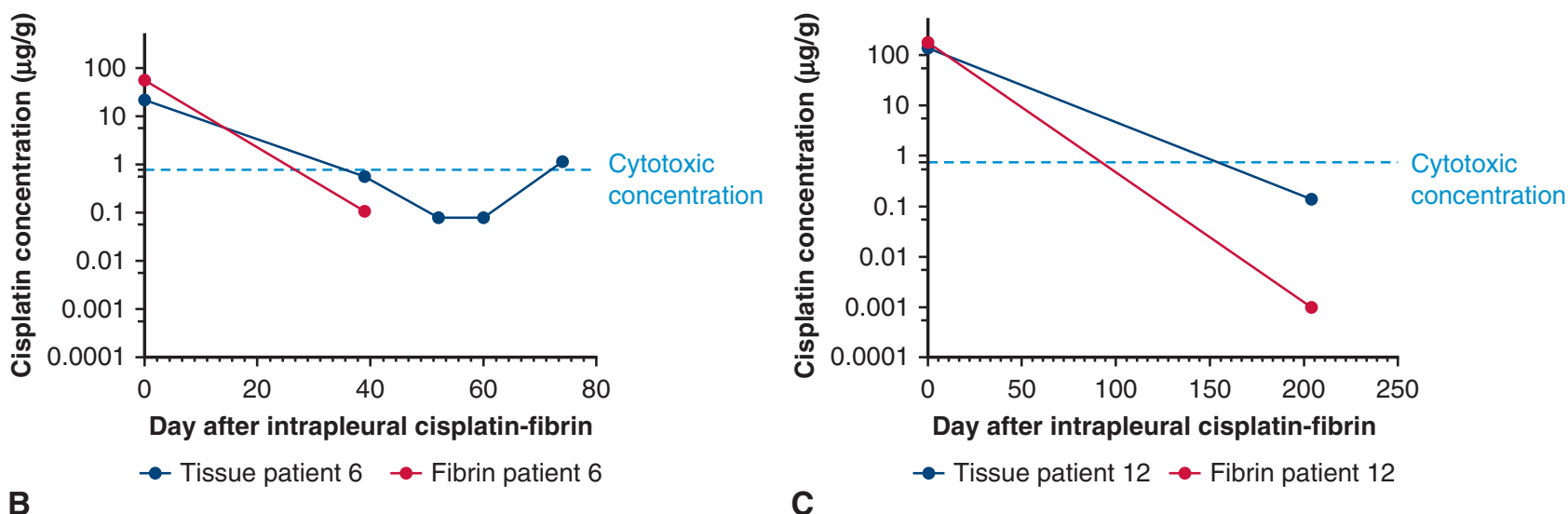

FIGURE 4. Levels of cisplatin in tissues of 12 patients with MPM receiving 4 different dosages of cisplatin-fibrin $\left(11,22,33\right.$, and $44 \mathrm{mg} / \mathrm{m}^{2} \mathrm{BSA} ; \mathrm{n}=3$ per group) after (extended) pleurectomy/decortication. A, Cisplatin concentration in the tissue biopsies collected before treatment ( 0 minute) and at 90 minutes after cisplatin-fibrin administration. Sample from 1 patient receiving dose level $44 \mathrm{mg} / \mathrm{m}^{2}$ BSA was lost during the analysis. High tissue cisplatin concentration above cytotoxic cisplatin concentration (blue line) was detected compared with tissues before cisplatin-fibrin administration (attributable to cisplatin applied during induction chemotherapy). B, Levels of cisplatin in tissues and gel samples of patients 6 (receiving $22 \mathrm{mg} / \mathrm{m}^{2} \mathrm{BSA}$ ) collected at several days after the treatment compared with 90 minutes (day 0). Levels of tissue cisplatin decreased from 90 minutes but still remained above cytotoxic concentration at day 74 after the administration. C, Tissues and gel samples of patients 12 (receiving $44 \mathrm{mg} / \mathrm{m}^{2} \mathrm{BSA}$ ) collected at day 204 compared with day 0 . Cisplatin was detectable at day 204 after the treatment but decreased below the cytotoxic concentration. Cytotoxic cisplatin concentration $(2.5 \mu \mathrm{mol} / \mathrm{L}$ or $0.75 \mu \mathrm{g} / \mathrm{g}$ ) represents cisplatin concentration that effectively inhibits proliferation of most of MPM cell lines in vitro during 5 days exposure 22,23 (unpublished data, cisplatin MPM growth and survival assays, various dates). Each dot represents the data from each individual patient, and bars represent median value of each group. $B S A$, Body surface area.

was lost to follow up. Median FFR was 8 months $(95 \%$ confidence interval [CI], 4-12), and 10 patients developed a relapse (in-treatment field recurrence) within 1 year after study treatment. In 1 patient with tumor stage $\mathrm{pT} 2 \mathrm{pN} 0$ and epithelioid MPM, who received $11 \mathrm{mg} / \mathrm{m}^{2}$ body surface area (BSA) without induction chemotherapy, relapse occurred 32 months after study treatment. One patient with $\mathrm{pT} 1 \mathrm{pN} 0$ and epithelioid MPM, who received $44 \mathrm{mg} / \mathrm{m}^{2}$ BSA with induction chemotherapy, is still without signs of recurrence at 52 months after study treatment. Median OS was 21 months (95\% CI, 10-31), and 1 patient included in the study is still alive after 4 years.

\section{DISCUSSION}

This is the first report on the safety of local therapy for patients with MPM, with potential use for other malignancies with diffuse growth and minimal resection margins. Cisplatin administered with fibrin is feasible and safe with no dose-limiting toxicity up to $44 \mathrm{mg} / \mathrm{m}^{2}$ BSA even in combination with neoadjuvant treatment. There 


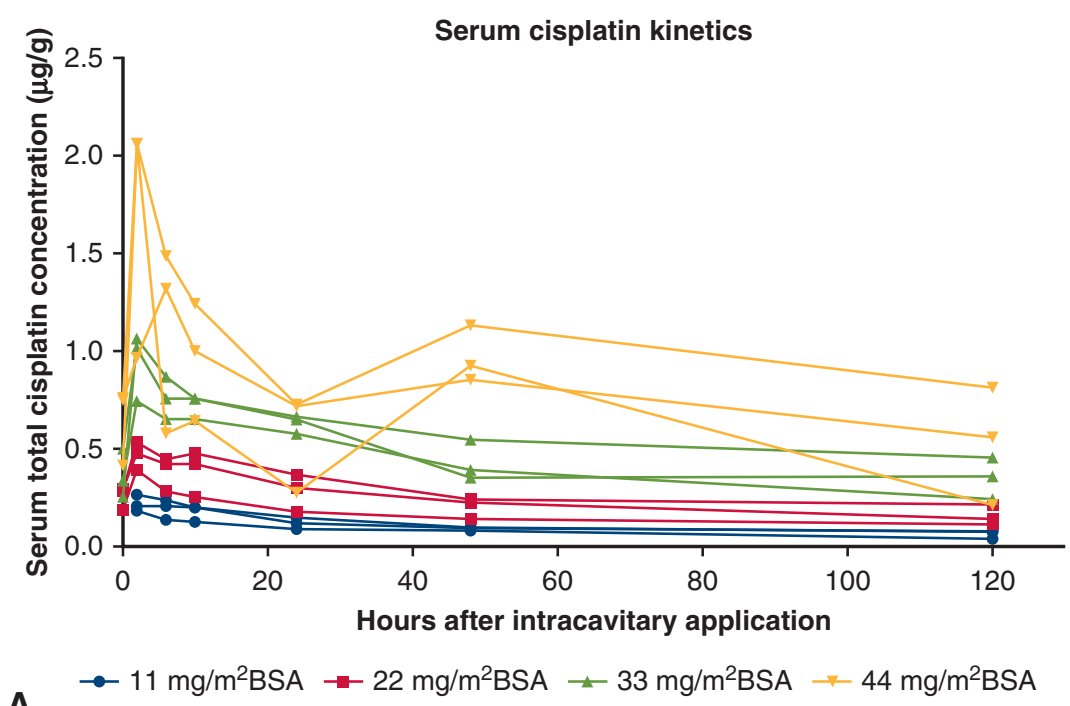

A

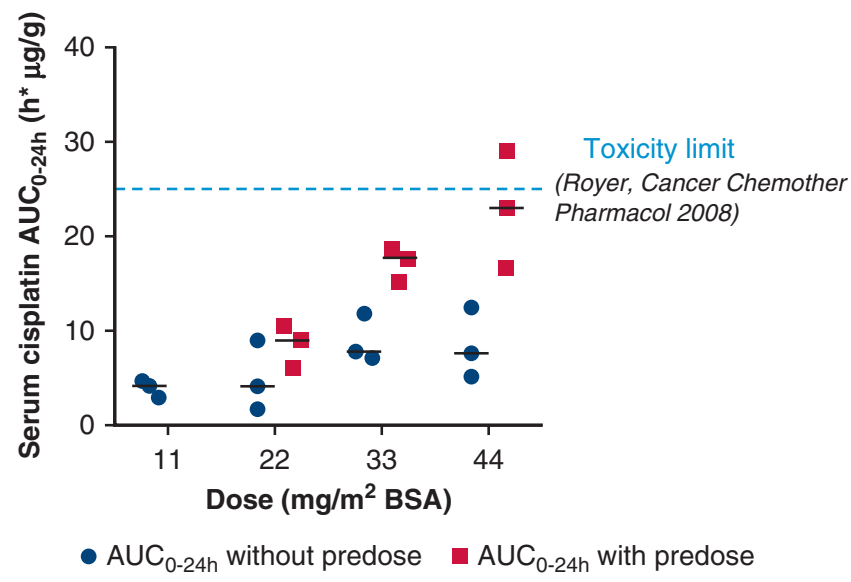

B

- $\mathrm{AUC}_{0-24 \mathrm{~h}}$ without predose $\quad \mathrm{AUC}_{0-24 \mathrm{~h}}$ with predose

FIGURE 5. Pharmacokinetic analysis of cisplatin in biological fluids of 12 patients with MPM receiving 4 different dosages of cisplatin-fibrin (11, 22, 33, and $44 \mathrm{mg} / \mathrm{m}^{2}$ BSA; $\mathrm{n}=3$ per group) after (extended) pleurectomy/decortication. A, Kinetics of cisplatin in serum after intrapleural cisplatin-fibrin administration. Serum cisplatin reached the peak at 2 hours after the administration and declined over time. B, AUC of serum cisplatin after intrapleural cisplatin-fibrin administration. AUCs were calculated from total cisplatin (with predose) that includes cisplatin administered during induction chemotherapy and as AUC due to cisplatin-fibrin only (without predose). Serum cisplatin due to intrapleural cisplatin-fibrin never exceeded renal toxicity limit of $25 \mathrm{~h}^{*} \mu \mathrm{g} / \mathrm{g}^{24,25}$ in all dosages. C, Total cisplatin excreted in urine and pleural effusion over a period of 48 hours. A larger proportion of cisplatin was excreted in urine, whereas excretion in pleural effusion did not increase with increasing dosage. Each dot represents the data from each individual patient, bars represent median value of each group. $B S A$, Body surface area; $A U C_{0-24 h}$, area under the concentration versus time curve during the first 24 hours; $P E$, pleural effusion; $S U M$, the sum of.

was a high local tissue cisplatin concentration in the chest wall after the treatment in some patients at long term, whereas the systemic distribution and exposure of cisplatin are below the threshold for renal toxicity (Figure 6). ${ }^{24,25}$ Although this dose-escalating study was not powered to investigate the efficacy or benefit of the cisplatin-fibrin on OS or FFR, we observed similar survival in these patients with advanced stage (75\% III-IV stage disease) compared with other multimodality treatments $(21$ months median OS).
According to new guidelines, intracavitary treatments are only recommended within clinical trial protocols and not yet administered in a standardized way. ${ }^{26}$ The reasons for this are a lack of evidence in terms of efficacy and scarcity of data for a clear pharmacokinetic advantage. In particular, local chest wall tissue concentrations of administered drugs are missing. This study contributes more detailed data about cisplatin pharmacokinetics.

This new way of administration is the main difference to other intracavitary therapies. We dispensed cisplatin bound 

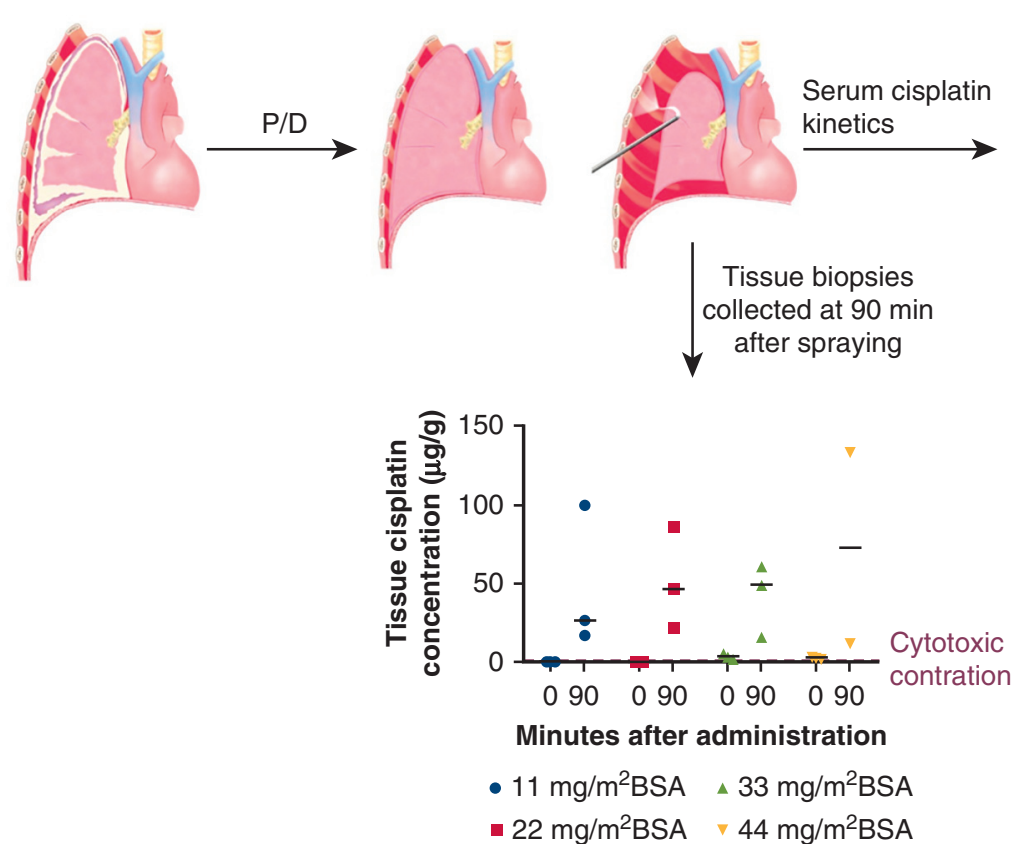

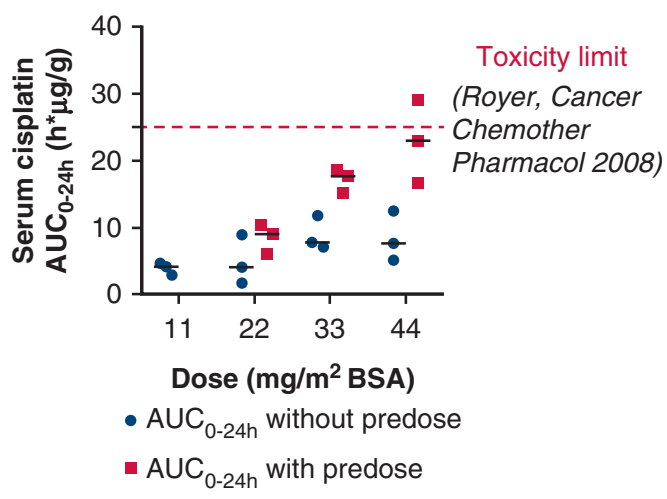

- $\mathrm{AUC}_{0-24 \mathrm{~h}}$ with predose

FIGURE 6. After (extended) pleurectomy/decortication, cisplatin-fibrin was applied on the thoracic wall and the lung surface. Levels of cisplatin were determined in serum collected at several time points and in tissue biopsies collected at 90 minutes after the administration. AUC $0-24 \mathrm{~h}$ of serum cisplatin attributable to cisplatin-fibrin only was calculated by the subtraction of predose (intravenous induction chemotherapy). AUC $0-24 \mathrm{~h}$ levels from cisplatin-fibrin were below nephrotoxic levels, and tissue cisplatin concentrations were high above the cytotoxic concentration after intrapleural cisplatin-fibrin administration. $P / D$, Pleurectomy/decortication; $A U C_{0-24 h}$, area under the concentration versus time curve during the first 24 hours; $B S A$, body surface area.

to fibrin by spraying it onto all resected surfaces. This is in contrast to other studies, in which intrathoracic application of cisplatin as a solution was mainly by pleural perfusion with or without hyperthermia, ${ }^{6,7,27}$ meaning only perioperative exposition. One problem of the perfusion studies is that the washout of the drug remains unclear because the chest cavity is drained with chest tubes after the procedure. In the present study, we observed constant levels, and not an increase of cisplatin concentrations in the pleural effusion even on the highest dose level during the first 48 hours, which indicates that cisplatin may stay locally on the chest wall and is not shed into the pleural space. Confirming these data, we have proven cytotoxic cisplatin concentration in the chest wall tissues in all treated patients. These tissue values are above the required toxicity level of $0.75 \mu \mathrm{g} / \mathrm{g}(2.5 \mu \mathrm{mol} / \mathrm{L})^{22,23}$ (unpublished data, cisplatin MPM growth and survival assays, various dates). To our knowledge, there is only one other study ${ }^{11}$ that measured cisplatin concentration in chest wall tissue samples $(3.96 \mu \mathrm{g} / \mathrm{g})$ after 1 hour of intrapleural hyperthermic perfusion with cisplatin $\left(100 \mathrm{mg} / \mathrm{m}^{2}\right.$ BSA) in humans. Compared with this study, our values from tissue biopsies measured at 90 minutes have been at least 3 times higher until up to $72.2 \mu \mathrm{g} / \mathrm{g}$ at the highest dose level. Cisplatin remained in the tissues collected from 1 patient during redo-surgery at 74 days after the administration.

The lack of dose-dependent and high variation of tissue cisplatin concentration can be explained by different hypotheses that cannot be proven in the current trial. First, even with highly standardized biopsy procedure, there might be variability of sample quality in terms of size and depth of biopsy. Second, cisplatin concentration in fibrin is the same for all dose levels; the higher dosage received more of cisplatin-fibrin mixture (thicker gel layer). Because drug exposure at the tissue-fibrin interface remains the same, the tissue concentration at 90 minutes did not change when a higher dosage was applied but may maintain higher drug concentration in tissue at a later time point. Third, cisplatin concentration in tissues may have reached the saturation.

The maximum tolerated dose was not reached, because no dose-limiting toxicity was observed, probably because of the pharmacokinetic advantage. Previous studies showed that one of the main perioperative and postoperative complications after intracavitary cisplatin perfusion with hyperthermia was renal toxicity, in some cases even renal failure. ${ }^{28,29}$ We observed creatinine levels above grade III toxicity in only 1 patient, which was due to a postoperative hypovolemic shock. In addition, even if 


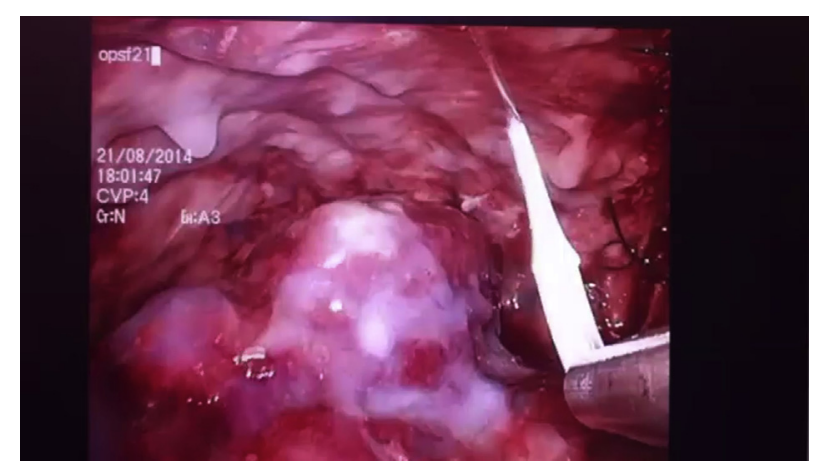

VIDEO 1. Thoracoscopic view during intracavitary cisplatin-fibrin application: spray-pen and cisplatin-fibrin (white gel). Video available at: https://www.jtcvs.org/article/S0022-5223(19)31613-7/fulltext.

cisplatin exposure from the induction intravenous administration was not subtracted, AUC values remained below thresholds for nephrotoxicity. ${ }^{24,25}$ Only $10 \%$ to $27 \%$ of the total cisplatin was excreted in the urine within the first 48 hours. Further support for good tolerability of the treatment includes the observed 30-day and 90-day mortality rates $0 \%$ for both and the low major morbidity rate of $33 \%$. This is in the lower range of the morbidity and mortality rates of $13 \%$ to $85 \%$ and $0 \%$ to $29 \%$, respectively, described in the literature after intracavitary chemotherapies. ${ }^{7,9,30}$

Comparison of cisplatin pharmacokinetics with other studies was difficult because of the different dosages of cisplatin administered, methods of measurements, time points, and measurement units. It is important to mention that although lower cisplatin doses were administered in our study, cisplatin-fibrin adhering to tissue may result in a longer drug exposure time compared with short intrapleural cisplatin perfusion and higher concentrations.

For the purpose of comparison, it can be assumed that $1 \mathrm{~g}$ serum is equivalent to $1 \mathrm{~mL}$, and free cisplatin concentrations are approximately $10 \%$ of the total cisplatin concentrations, according to Ehrsson. ${ }^{31}$ A study by Ried and colleagues ${ }^{30}$ of 8 patients with MPM and 8 patients with pleural manifestation of thymoma (Masaoka stage IVa) receiving $100 \mathrm{mg} / \mathrm{m}^{2}$ BSA intrapleural hyperthermic cisplatin perfusion reported $\mathrm{AUC}_{0-24 \mathrm{~h}}$ of $534.0 \mathrm{~min} * \mu \mathrm{g} / \mathrm{mL}$ for free cisplatin (corresponding to $5340 \mathrm{~min}^{*} \mu \mathrm{g} / \mathrm{mL}$ for total cisplatin), which is 3.9 times higher than the median $\mathrm{AUC}_{0-24 \mathrm{~h}}$ of the dose level 4 in our study (1380 $\mathrm{min}^{*} \mu \mathrm{g} / \mathrm{mL}$ for total cisplatin).

\section{Study Limitations}

Despite the limitations for direct comparison, our data show a tendency toward better pharmacokinetics in terms of systemic distribution and prolonged local efficacy. The trial was not powered to answer efficacy questions, and there was high variation of clinical outcomes. Nevertheless, the preliminary analysis showed a median FFR of 8 months (95\% CI, 4-12 months). The median OS of 21 months ( $95 \%$ CI, 10-31 months) in this cohort of patients with advanced stage disease is in the range of other studies on intracavitary chemotherapy, which described median OS rates of 12.8 to 35.3 months. $6,7,32,33$

The small sample size leads to known limitations because of heterogeneous groups in terms of stage and treatment. Overall, we observed a high variability in the pharmacokinetic measurements most likely due to this new way of application. To overcome this limitation, we tried to standardize the application procedure, the process of sampling, and the analytical method for cisplatin. Another disadvantage of the present study is that the study was planned for a maximum dose of $44 \mathrm{mg} / \mathrm{m}^{2}$. Further increase of the dosages was not feasible because of technical limitations during the application process. The main technical limitations are (1) large amount of fresh-frozen plasma needed; (2) longer time require for fibrin preparation; and (3) longer duration of cisplatinfibrin administration. Thus, dose escalation beyond this level is not reasonable in particular because of the extension of operating times. Because our pharmacokinetics already showed high, cytotoxic concentrations compared with previous intrapleural chemotherapy solution studies, ${ }^{11}$ we are currently evaluating the effectiveness of the highest dose level. The data regarding the efficacy will justify whether higher dosage is necessary.

\section{CONCLUSIONS}

This new therapy approach with intracavitary cisplatin fibrin application after (extended) pleurectomy/decortication is safe and feasible up to the maximum cisplatin concentration of $44 \mathrm{mg} / \mathrm{m}^{2}$ BSA. The concomitant application of a sealant such as fibrin is expected to provide a more continuous and slower drug release over time with persistently high drug concentrations in the local chest wall tissues and at the same time low systemic concentrations, which could be confirmed. Fibrin can also be used for intrapleural administration of new effective therapeutic agents as well as for other indications, such as anti-infection treatment. Preliminary efficacy data are promising, and currently a phase II trial is being conducted to confirm the safety and gain more data regarding efficacy of $44 \mathrm{mg} / \mathrm{m}^{2}$ BSA cisplatin-fibrin in a larger patient cohort.

\section{Conflict of Interest Statement}

Vivostat SA sponsored the kits for the application, but there is no conflict of interest to the authors. All authors have nothing to disclose with regard to commercial support.

The authors thank Dr Dorothe Veraguth for the assessment of the audiometry and Dr Chloe Spichiger for support in the edition 
of the article; the whole team of Thoracic Surgery for supporting the trial; Dr Martina Friess for documentation of clinical data and data management; Cordelia Bommeli as study coordinator; Dr Michaela Kirschner for scientific input; Dr Emanuela Felley-Bosco for literature research and calculation for the dosages in the dose-escalation design; and Guillaume Wuilleret, Gian-Marco Monsch, and Arthur Kostron for support in data collection for this study.

\section{References}

1. Krug LM, Pass HI, Rusch VW, Kindler HL, Sugarbaker DJ, Rosenzweig KE, et al. Multicenter phase II trial of neoadjuvant pemetrexed plus cisplatin followed by extrapleural pneumonectomy and radiation for malignant pleural mesothelioma. J Clin Oncol. 2009;27:3007-13.

2. Weder W, Stahel RA, Bernhard J, Bodis S, Vogt P, Ballabeni P, et al. Multicenter trial of neo-adjuvant chemotherapy followed by extrapleural pneumonectomy in malignant pleural mesothelioma. Ann Oncol. 2007;18:1196-202.

3. de Perrot M, Feld R, Cho BC, Bezjak A, Anraku M, Burkes R, et al. Trimodality therapy with induction chemotherapy followed by extrapleural pneumonectomy and adjuvant high-dose hemithoracic radiation for malignant pleural mesothelioma. J Clin Oncol. 2009;27:1413-8.

4. Cao C, Tian D, Park J, Allan J, Pataky KA, Yan TD. A systematic review and meta-analysis of surgical treatments for malignant pleural mesothelioma. Lung Cancer. 2014;83:240-5.

5. Colaut F, Toniolo L, Vicario G, Scapinello A, Visentin C, Manente P, et al. Pleurectomy/decortication plus chemotherapy: outcomes of 40 cases of malignant pleural mesothelioma. Chir Ital. 2004;56:781-6.

6. Tilleman TR, Richards WG, Zellos L, Johnson BE, Jaklitsch MT, Mueller J, et al. Extrapleural pneumonectomy followed by intracavitary intraoperative hyperthermic cisplatin with pharmacologic cytoprotection for treatment of malignant pleural mesothelioma: a phase II prospective study. J Thorac Cardiovasc Surg. 2009; 138:405-11.

7. Richards WG, Zellos L, Bueno R, Jaklitsch MT, Janne PA, Chirieac LR, et al. Phase I to II study of pleurectomy/decortication and intraoperative intracavitary hyperthermic cisplatin lavage for mesothelioma. J Clin Oncol. 2006;24:1561-7.

8. Rusch V, Saltz L, Venkatraman E, Ginsberg R, McCormack P, Burt M, et al. A phase II trial of pleurectomy/decortication followed by intrapleural and systemic chemotherapy for malignant pleural mesothelioma. J Clin Oncol. 1994;12: 1156-62.

9. Rice TW, Adelstein DJ, Kirby TJ, Saltarelli MG, Murthy SR, Van Kirk MA, et al. Aggressive multimodality therapy for malignant pleural mesothelioma. Ann Thorac Surg. 1994;58:24-9.

10. Rusch VW, Niedzwiecki D, Tao Y, Menendez-Botet C, Dnistrian A, Kelsen D, et al. Intrapleural cisplatin and mitomycin for malignant mesothelioma following pleurectomy: pharmacokinetic studies. J Clin Oncol. 1992;10:1001-6.

11. Ratto GB, Civalleri D, Esposito M, Spessa E, Alloisio A, De Cian F, et al. Pleural space perfusion with cisplatin in the multimodality treatment of malignant mesothelioma: a feasibility and pharmacokinetic study. J Thorac Cardiovasc Surg. 1999; 117:759-65.

12. de Bree E, van Ruth S, Baas P, Rutgers EJ, van Zandwijk N, Witkamp AJ, et al. Cytoreductive surgery and intraoperative hyperthermic intrathoracic chemotherapy in patients with malignant pleural mesothelioma or pleural metastases of thymoma. Chest. 2002;121:480-7.

13. van Ruth S, Baas P, Haas RL, Rutgers EJ, Verwaal VJ, Zoetmulder FA. Cytoreductive surgery combined with intraoperative hyperthermic intrathoracic chemotherapy for stage I malignant pleural mesothelioma. Ann Surg Oncol. 2003;10:176-82.

14. Mandell SP, Gibran NS. Fibrin sealants: surgical hemostat, sealant and adhesive. Expert Opin Biol Ther. 2014;14:821-30.

15. Moser C, Opitz I, Zhai W, Rousson V, Russi EW, Weder W, et al. Autologous fibrin sealant reduces the incidence of prolonged air leak and duration of chest tube drainage after lung volume reduction surgery: a prospective randomized blinded study. J Thorac Cardiovasc Surg. 2008;136:843-9.
16. Opitz I, Lardinois D, Arni S, Hillinger S, Vogt P, Odermatt B, et al. Local recurrence model of malignant pleural mesothelioma for investigation of intrapleural treatment. Eur J Cardiothorac Surg. 2007;31:773-8.

17. Lardinois D, Jung FJ, Opitz I, Rentsch K, Latkoczy C, Vuong V, et al. Intrapleural topical application of cisplatin with the surgical carrier Vivostat increases the local drug concentration in an immune-competent rat model with malignant pleuromesothelioma. J Thorac Cardiovasc Surg. 2006;131:697-703.

18. Opitz I, Erne BV, Demirbas S, Jetter A, Seifert B, Stahel R, et al. Optimized intrapleural cisplatin chemotherapy with a fibrin carrier after extrapleural pneumonectomy: a preclinical study. J Thorac Cardiovasc Surg. 2011;141:65-71.

19. Kostron A, Friess M, Inci I, Hillinger S, Schneiter D, Gelpke H, et al. Propensity matched comparison of extrapleural pneumonectomy and pleurectomy/decortication for mesothelioma patients. Interact Cardiovasc Thorac Surg. 2017;24: 740-6.

20. Zimmermann S, Menzel CM, Berner Z, Eckhardt J-D, Stüben D, Alt F, et al. Trace analysis of platinum in biological samples: a comparison between sector field ICP-MS and adsorptive cathodic stripping voltammetry following different digestion procedures. Analytica Chimica Acta. 2001;439:203-9.

21. Karlsson MO, Bredberg U. Estimation of bioavailability on a single occasion after semisimultaneous drug administration. Pharm Res. 1989;6:817-21.

22. Cortes-Dericks L, Carboni GL, Schmid RA, Karoubi G. Putative cancer stem cells in malignant pleural mesothelioma show resistance to cisplatin and pemetrexed. Int J Oncol. 2010;37:437-44.

23. Gordon GJ, Mani M, Maulik G, Mukhopadhyay L, Yeap BY, Kindler HL, et al. Preclinical studies of the proteasome inhibitor bortezomib in malignant pleural mesothelioma. Cancer Chemother Pharmacol. 2008;61:549-58.

24. Guardiola E, Delroeux D, Heyd B, Combe M, Lorgis V, Demarchi M, et al. Intraoperative intra-peritoneal chemotherapy with cisplatin in patients with peritoneal carcinomatosis of ovarian cancer. World J Surg Oncol. 2009;7:14.

25. Royer B, Delroeux D, Guardiola E, Combe M, Hoizey G, Montange D, et al. Improvement in intraperitoneal intraoperative cisplatin exposure based on pharmacokinetic analysis in patients with ovarian cancer. Cancer Chemother Pharmacol. 2008;61:415-21.

26. Kindler HL, Ismaila N, Armato SG III, Bueno R, Hesdorffer M, Jahan T, et al. Treatment of malignant pleural mesothelioma: American Society of Clinical Oncology clinical practice guideline. J Clin Oncol. 2018;36:1343-73.

27. Sugarbaker PH, Stuart OA, Eger C. Pharmacokinetics of hyperthermic intrathoracic chemotherapy following pleurectomy and decortication. Gastroenterol Res Pract. 2012;2012:471205.

28. Zellos L, Richards WG, Capalbo L, Jaklitsch MT, Chirieac LR, Johnson BE, et al. A phase I study of extrapleural pneumonectomy and intracavitary intraoperative hyperthermic cisplatin with amifostine cytoprotection for malignant pleural mesothelioma. J Thorac Cardiovasc Surg. 2009;137:453-8.

29. Colleoni M, Sartori F, Calabro F, Nelli P, Vicario G, Sgarbossa G, et al. Surgery followed by intracavitary plus systemic chemotherapy in malignant pleural mesothelioma. Tumori. 1996;82:53-6.

30. Ried M, Potzger T, Braune N, Neu R, Zausig Y, Schalke B, et al. Cytoreductive surgery and hyperthermic intrathoracic chemotherapy perfusion for malignant pleural tumours: perioperative management and clinical experience. Eur J Cardiothorac Surg. 2013;43:801-7.

31. Ehrsson H. Population pharmacokinetics and dosing recommendations for cisplatin during intraperitoneal peroperative administration. Clin Pharmacokinet. 2009;48:685-6. author reply 686-7.

32. Hasani A, Alvarez JM, Wyatt JM, Bydder S, Millward M, Byrne M, et al. Outcome for patients with malignant pleural mesothelioma referred for trimodality therapy in Western Australia. J Thorac Oncol. 2009;4:1010-6.

33. Sugarbaker DJ, Gill RR, Yeap BY, Wolf AS, DaSilva MC, Baldini EH, et al. Hyperthermic intraoperative pleural cisplatin chemotherapy extends interval to recurrence and survival among low-risk patients with malignant pleural mesothelioma undergoing surgical macroscopic complete resection. J Thorac Cardiovasc Surg. 2013;145:955-63.

Key Words: cisplatin, fibrin, intracavitary, malignant pleural mesothelioma, phase I study 


\section{APPENDIX E1. METHODS}

\section{Selection of Dosage and Dose-Escalation Scheme}

The maximum tolerated dose of intracavitary cisplatinsolution was evaluated in phases I and II dose-escalation designs and was reported to be $225 \mathrm{mg} / \mathrm{m}^{2}$ BSA in humans. ${ }^{\text {E1,E2 }}$ Cisplatin-fibrin has not been used in a clinical setting yet. In our small animal (rats) preclinical model, ${ }^{\mathrm{E} 3}$ a dose of $24 \mathrm{mg} / \mathrm{m}^{2}$ BSA was already efficient in significantly reducing tumor recurrence. In our large animal (pigs) preclinical pharmacokinetic model, ${ }^{\mathrm{E} 4}$ we applied a dose of $5 \mathrm{mg}$ cisplatin-fibrin/100 $\mathrm{cm}^{2}$ pleural surface ( $=46.9 \mathrm{mg} / \mathrm{m}^{2}$ BSA) without observation of any toxic effect. Together with the Department of Radiology, we measured by volumetry the surface of the parietal pleura including the mediastinal pleura (without the hilar structures) of 4 patients with mesothelioma, and the median surface of the parietal pleura was $1270 \mathrm{~cm}^{2}\left(0.13 \mathrm{~m}^{2}\right)$. To cover the whole pleural surface with cisplatin-fibrin, a total dose of $65 \mathrm{mg}$ cisplatin $(5 \times 13)$ will be applied. Assuming that a patient with $70 \mathrm{~kg}$ and $170 \mathrm{~cm}$ has a BSA of $1.82 \mathrm{~m},{ }^{\mathrm{E} 2, \mathrm{E} 5}$ calculated on BSA this dose corresponds to a dose of $33.0 \mathrm{mg} / \mathrm{m}^{2}$ BSA of cisplatin.

There are several approaches used in the literature to determine the appropriate dose for a first-in-man-study in oncology (which is different to first-in-man considerations in other therapeutic areas with noncytotoxic drugs). ${ }^{\mathrm{E} 6, \mathrm{E} 7}$ One approach is to use one-third of the "toxic dose low," defined as the lowest dose in a large animal species that produced drug-related adverse effects and that did not cause any fatality when doubled. Because for the cisplatin-fibrin sealant, only 1 dose level equivalent to $33 \mathrm{mg} / \mathrm{m}^{2}$ BSA was tested in pigs and no drug-related adverse effect was observed, ${ }^{\mathrm{E} 4}$ the so-called no observable adverse effect level (NOAEL) is at least $33 \mathrm{mg} / \mathrm{m}^{2} \mathrm{BSA}$. Because the toxic dose low is higher than the NOAEL, it is reasonable to assume that a human starting dose of one-third of the NOAEL dose, that is, $11 \mathrm{mg} / \mathrm{m}^{2}$ BSA, should be safe. Additional support comes from the knowledge that maximum tolerated doses of intracavitary cisplatin are reported to be $225 \mathrm{mg} / \mathrm{m}^{2}$ BSA without fibrin sealant.

In the present study, the starting dose is set to approximately $1 / 20$ of the maximum tolerated dosage in humans without fibrin, which can also be considered reasonably safe, particularly because it is expected that cisplatin will be less absorbed from the pleural cavity when it is administered in the fibrin matrix than when administered as solution. For these reasons, we will start with a dose of $11 \mathrm{mg}$ cisplatin-fibrin $/ \mathrm{m}^{2}$ BSA. The dose level will be increased as described in the Table seen below and, if maximum tolerated dosage is not reached, ${ }^{\mathrm{E} 8}$ the phase I study will be finished with a dose of $44 \mathrm{mg}$ cisplatin-fibrin $/ \mathrm{m}^{2}$ BSA. Three to 6 patients per dose level will be included in phase I, so a minimum of 12 and a maximum of 24 patients will be included, if all 4 dose levels are successfully completed. This scheme is considered as standard for a clinical dose-escalation study in the section 5.2 of the clinical trial protocol's template of the National Cancer Institute. ${ }^{\text {E8 }}$

\begin{tabular}{|c|c|}
\hline Dose level & $\begin{array}{c}\text { Cisplatin-fibrin (per } \mathrm{m}^{2} \\
\text { BSA) }\end{array}$ \\
\hline 1 & $11 \mathrm{mg}$ \\
\hline 2 & $22 \mathrm{mg}$ \\
\hline 3 & $33 \mathrm{mg}$ \\
\hline 4 & $44 \mathrm{mg}$ \\
\hline
\end{tabular}

\section{Preparation of fibrin}

Fibrin was prepared on the same day of application from fresh-frozen plasma from matching blood group donors, using Vivostat fibrin processing kits and Vivostat PRO-800 processors, ${ }^{\mathrm{E} 4}$ and stored at $4^{\circ} \mathrm{C}$ until used. Syringes containing $5.7 \mathrm{~mL}$ fibrin, $1.1 \mathrm{~mL}$ buffer $\mathrm{pH} 10$, and $5.7 \mathrm{~mL}$ of cisplatin (Actavis [Dublin, Ireland], $1 \mathrm{mg} / \mathrm{mL}$ ) were loaded to the Vivostat application system. The machine sprays the 3 components to the targeted surface area through a Vivostat endoscopic co-delivery tube producing a fibrin gel containing cisplatin. Spray loads were repeated until the target dose was reached.

\section{E-References}

E1. Richards WG, Zellos L, Bueno R, Jaklitsch MT, Jänne PA, Chirieac LR, et al Phase I to II study of pleurectomy/decortication and intraoperative intracavitary hyperthermic cisplatin lavage for mesothelioma. J Clin Oncol. 2006;24:1561-7.

E2. Chang MY, Sugarbaker DJ. Innovative therapies: intraoperative intracavitary chemotherapy. Thorac Surg Clin. 2004;14:549-56.

E3. Opitz I, Lardinois D, Arni S, Hillinger S, Vogt P, Odermatt B, et al. Local recurrence model of malignant pleural mesothelioma for investigation of intrapleural treatment. Eur J Cardiothorac Surg. 2007;31:773-8.

E4. Opitz I, Erne BV, Demirbas S, Jetter A, Seifert B, Stahel R, et al. Optimized intrapleural cisplatin chemotherapy with a fibrin carrier after extrapleural pneumonectomy: a preclinical study. J Thorac Cardiovasc Surg. 2011;141:65-71.

E5. Mosteller RD. Simplified calculation of body-surface area. N Engl J Med. 1987; 317:1098

E6. Reigner BG, Blesch KS. Estimating the starting dose for entry into humans: principles and practice. Eur J Clin Pharmacol. 2002;57:835-45.

E7. Penel N, Leblond P, Lansiaux A, Clisant S, Dansin E, Adenis A, et al. Justification of the starting dose as the main determinant of accrual time in dose-seeking oncology phase 1 trials. Invest New Drugs. 2010;28:839-43.

E8. National Cancer Institute. Protocol templates and guidelines. Suggested templates for phase 1 and 2 clinical trials. Available at: https://ctep.cancer.gov/ protocolDevelopment/templates_applications.htm. Accessed September 24, 2019. 


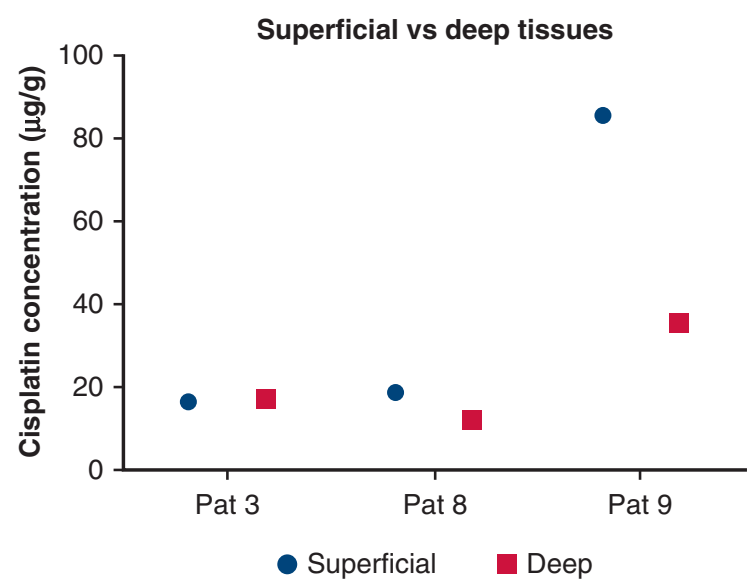

FIGURE E1. Analysis of cisplatin concentration in the tissue directly attached to cisplatin-fibrin gel (superficial) and tissue layer directly underneath the superficial layer from the same location obtained in a second step including more of the intercostal muscles (deep) collected at 90 minutes after cisplatin-fibrin administration. Data are available from 3 patients, including patients 3,8 , and 9 receiving 11,33 , and $33 \mathrm{mg} / \mathrm{m}^{2}$ BSA cisplatin, respectively. High cisplatin concentration in deeper tissue suggests that cisplatin diffused into deeper tissue layer during the 90-minute exposure. Each dot represents the data from each individual patient, bars represent median value of each group.

TABLE E1. Inclusion and exclusion criteria for the INFLuenCe-Meso I study

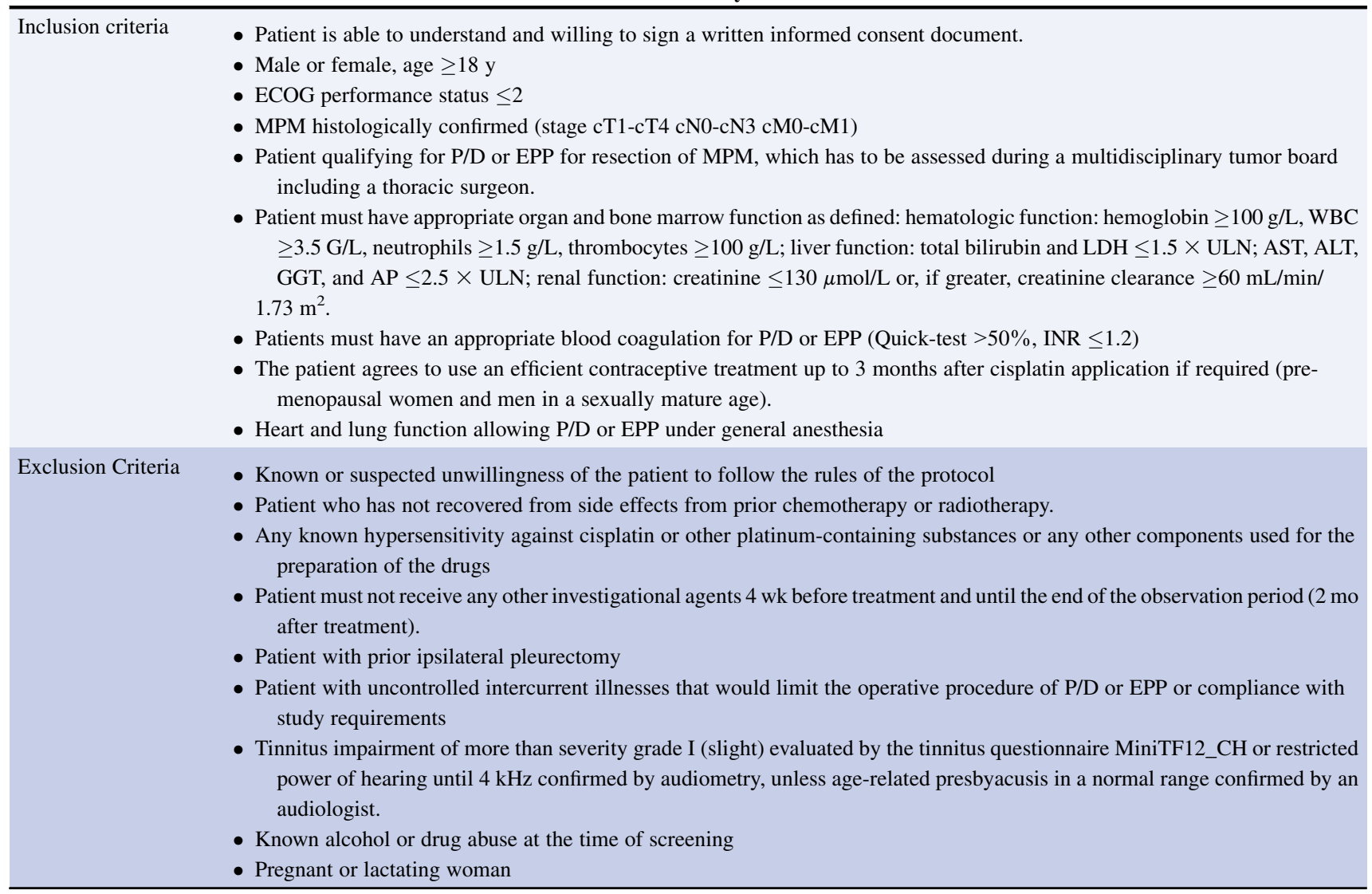

ECOG, Eastern Cooperative Oncology Group; $M P M$, malignant pleural mesothelioma; $P / D$, pleurectomy/decortication; $E P P$, extrapleural pneumonectomy; $W B C$, white blood cell; $L D H$, lactate dehydrogenase; $U L N$, upper limit of normal; $A L T$, Alanine transaminase; $A S T$, aspartate transaminase; $G G T$, gamma-glutamyl transpeptidase; $A P$, alkaline phosphatase; $I N R$, international normalized ratio. 
TABLE E2. Study protocol of the INFLuenCe-Meso I study

\begin{tabular}{|c|c|c|c|c|c|c|c|c|}
\hline \multirow{2}{*}{$\frac{\text { Study parts }}{\text { Visit }}$} & \multirow{2}{*}{$\frac{\text { Screening* }}{1}$} & \multirow{2}{*}{$\frac{\text { Enrollment }}{2}$} & \multirow{2}{*}{$\frac{\text { Treatment }}{3}$} & \multicolumn{3}{|c|}{ Observation } & \multicolumn{2}{|c|}{ Poststudy observation } \\
\hline & & & & 4 & 5 & 6 & 7 & 8 \\
\hline Day (wk) & $\begin{array}{c}-42 d \\
\text { to }-2 d\end{array}$ & $\begin{array}{c}-2 \text { to } \\
\text { 0 d }\end{array}$ & $\mathbf{0} \mathbf{d}$ & $\begin{array}{l}0-14 \text { d } \\
(2 w k)\end{array}$ & $\begin{array}{c}28 \mathrm{~d} \\
(4 \mathrm{wk}) \\
\pm 14 \mathrm{~d}\end{array}$ & $\begin{array}{c}56 \mathrm{~d} \\
(8 \mathrm{wk}) \\
\pm 14 \mathrm{~d}\end{array}$ & $\begin{array}{c}112 \mathrm{~d} \\
(16 \mathrm{wk}) \\
\pm 14 \mathrm{~d}\end{array}$ & $\begin{array}{c}>112 \text { d } \\
\text { (every } \\
4 \text { mo), } \\
\pm 14 \text { d } \\
\text { until } 5 \mathrm{y}\end{array}$ \\
\hline Patient's written informed consent & $\mathrm{x}$ & & & & & & & \\
\hline Inclusion/exclusion criteria & & $\mathrm{x}$ & & & & & & \\
\hline Demographic data & $\mathrm{x}$ & & & & & & & \\
\hline Medical history & $x^{1}$ & $\mathrm{x}$ & $x^{2}$ & $x^{2}$ & $x^{2}$ & $x^{2}$ & $x^{2}$ & $x^{2}$ \\
\hline Physical examination & $\mathrm{x}$ & $x^{3}$ & & $x^{4}$ & $\mathrm{x}$ & $\mathrm{x}$ & $\mathrm{x}$ & $\mathrm{x}$ \\
\hline Vital signs & $\mathrm{x}$ & $\mathrm{x}$ & & $x^{4}$ & $\mathrm{x}$ & $\mathrm{x}$ & $\mathrm{x}$ & $\mathrm{x}$ \\
\hline Pregnancy test & $x^{5}$ & & & & & & & \\
\hline Chest X-ray & $x^{6}$ & $\mathrm{x}$ & & & & & & \\
\hline ECG & $\mathrm{x}$ & & & & & & & \\
\hline Audiometry or tinnitus test & $x^{7}$ & & & & $x^{7}$ & & & \\
\hline Laboratory analysis & $\mathrm{x}$ & $\mathrm{x}$ & & $x^{8}$ & $\mathrm{x}$ & $\mathrm{x}$ & & \\
\hline CT scan (chest cavity and upper abdomen) and volumetry & $x^{9}$ & & & & $\mathrm{x}$ & & $x^{10}$ & $x^{10}$ \\
\hline FDG-PET-CT/MRI and volumetry & $\mathrm{x}$ & & & & & & & $x^{10}$ \\
\hline Mediastinoscopy & $\mathrm{x}$ & & & & & & & \\
\hline Biopsy & $x^{11}$ & & $\mathrm{x}^{12,13}$ & $x^{14}$ & $x^{14}$ & $x^{14}$ & $x^{14}$ & $x^{14}$ \\
\hline Spirometry and diffusion capacity & $\mathrm{x}$ & & & & & & $\mathrm{x}$ & \\
\hline Lung perfusion scan & $\mathrm{x}$ & & & & & & & \\
\hline Echocardiography & $x^{15}$ & & & & & & & \\
\hline Tumor board & $\mathrm{x}$ & & & & $x^{16}$ & & $x^{17}$ & $x^{17}$ \\
\hline Patient's quality of life (SF36, EORTC QLQ-C15/LC13) & & $\mathrm{x}$ & & & $\mathrm{x}$ & $\mathrm{x}$ & $\mathrm{x}$ & $\mathrm{x}$ \\
\hline Surgery (P/D/EPP) & & & $\mathrm{x}$ & & & & & \\
\hline Cisplatin-fibrin & & & $\mathrm{x}$ & & & & & \\
\hline AEs & & $\mathrm{x}$ & $\mathrm{x}$ & $\mathrm{x}$ & $\mathrm{x}$ & $\mathrm{x}$ & $\mathrm{x}$ & $\mathrm{x}$ \\
\hline
\end{tabular}

ECG, Electrocardiogram; FDG-PET-CT/MRI, 18F-fluoro-2-deoxy-D-glucose positron-emission tomography computed tomography/magnetic resonance imaging; EORTC, European Organisation for Research and Treatment of Cancer; P/D/EPP, extended pleurectomy/decortication; SF36, Short Form 36; $A E$, adverse event.

*Screening: Data are accepted from routine assessments; these can be done on different days within 42 to 2 days before enrollment

1. Consumption of alcohol/nicotine, exposure to asbestos, concomitant medication, weight loss, chest pain, any pathology.

2. Concomitant medication concerning the perioperative course.

3. Weight and height for determination of BSA for dose calculation

4. In the context of daily rounds.

5. Unless infertile or postmenopausal. Patient's informed consent is compulsory for this assessment.

6. X-ray made less than $4 \mathrm{wk}$ before screening day will be accepted and not repeated on visit 1 .

7. Only if patient reported tinnitus or restricted power of hearing (especially in the upper frequency range). Patient's informed consent is compulsory for this assessment.

8. Blood samples for determination of cisplatin: baseline before treatment with cisplatin-fibrin only for patients who underwent previous platinol-based intravenous chemotherapy. All patients: blood sample collection at 2, 6, 10, 24, 48, and $120 \mathrm{~h}$ postoperative. Hematology and clinical chemistry at PODs $1,2,3,4,5,7,10,14$; urine collection: before treatment with cisplatin-fibrin, 0-48 h postoperative, and POD 14. Pleural effusion collection: 0-48 h postoperative.

9. Maximum 4 weeks before surgery. If patient undergoes induction chemotherapy, repeat CT for determination of response by modified Response Evaluation Criteria in Solid Tumors.

10. CT scan plus volumetry or FDG-PET-CT/MRI plus volumetry alternating every 4 mo.

11. If pleural biopsy was performed in another institution, and unless no induction chemotherapy is planned, re-biopsy will not be performed mandatorily during the same narcosis for video-mediastinoscopy (otherwise, biopsy under point 12 below will be used). Patient's informed consent would then be compulsory for this assessment.

12. For phase I patients to determine baseline cisplatin concentration in the superficial tissue of the chest wall. 
13. During phase I study, a thoracoscopic chest wall biopsy will be performed 90 minutes after cisplatin-fibrin application to determine cisplatin concentration in the superficial tissue of the chest wall (primary objective).

14. Further biopsies will be performed if clinically indicated for other reasons (eg, infection, pneumothorax, pericardial effusion), or if tumor recurrence is suspected. The most minimal invasive intervention has to be chosen.

15. If cardiac risk factors are known, such as cardiac valve dysfunction, heart insufficiency, heart hypertrophy, cardiac malformation, cardiomyopathy, and heart ischemia by coronary disease.

16. For discussion of final pathological results.

17. In case of tumor progression during follow-up. 